\title{
The model of creation of energy-saving competence of students of high school
}

\author{
Evald Zeer ${ }^{1}$, Elvira Symaniuk ${ }^{2}$, Anna Pecherkina $^{2}$, Anastasia Stepanova ${ }^{2 a}$, and Nina \\ Symaniuk $^{3}$ \\ ${ }^{1}$ Russian State Professional-Pedagogical University, 620012, Yekaterinburg, Russia \\ ${ }^{2}$ Ural Federal University named after the first President of Russia B.N. Yeltsin, 620002, \\ Yekaterinburg, Russia \\ ${ }^{3}$ Institute of Philosophy and Law, Ural Department of the Russian Academy of Sciences, 620144, \\ Yekaterinburg, Russia
}

\begin{abstract}
This article considers the most important conditions for the creationof energy-saving competence of students - undergraduate training. The actualityof the problem is caused by low energy efficiency of industrial production, significantly reduces the competitiveness of the domestic economy and, consequently, the need to intensify activities on the rational use of energy resources. The definition of energy-saving expertise, marked its structural components (value-motivational, cognitive activity-reflexive). Stages of creationof energy-saving expertise in system of continuous vocational training: diagnosis, motivation, learning and reflective-evaluative. The possibilities of educational technology and psycho designed to work with the psychological barriers and resistance to the process of regulation of energy consumption, the production facilities at its energy efficiency and energy saving. In particular, it is recommended to use active learning methods (discussion, games, analysis of problem situations, etc.), Information and communication technologies for the implementation of educational and research projects in the field of energy conservation, the development and implementation of interactive multimedia learning environments.
\end{abstract}

\section{Introduction to the problem}

In today's post-industrial society it becomes a problem energy-saving the survival of all humanity. This is evidenced by the world practice of rationing energy saving: UN documents, legislative measures of the European Union, USA, Japan, and the Federal Law of Russian Federation No. 261-FZ "About energy-saving..." (2009) and the federal government program of Russian Federation "Energy Efficiency and Energy Development" (2013).

The actualityof the problem of energy-saving is due to several factors. Energy efficiency can slow down the rate of consumption of energy resources, reduce the impact of production and consumption processes on the environment, preserve the stability

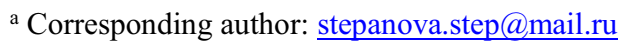


of the biosphere. Energy efficiency in every sphere is essentially reduced to reduce the useless loss of energy due to its rational use.

The energy intensity of industrial production and social services in Russia is several times higher than global indicators making our products uncompetitive, and life is unacceptable energy wastefulness. Russian manufacturer spends on production products on average three times more energy than the average world country.

The main legislative measures remain unfulfilled. One of the key reasons the underestimation of the importance and timeliness of formulation system of compulsory and voluntary energy management in enterprises, organizations and every individual. Improving the energy efficiency of natural resources necessitates the development of public cultural bases of energy resources consumption. It is necessary to overcome stereotype waste all and in all. Hence the need to create new ways of thinking power.

Reasonable power consumption can be a manifestation of a particular kind of competence - energy-saving expertise. Since the energy-saving activities are included in the different activities, it can be concluded that the relevant competence refers to the universal or key competences that go beyond the specific subject areas, and aimed at solving urgent social, economic and environmental problems. With regard to different types of professional activities, this expertise can be considered and as a base [1].

\section{The extend of a problem}

Analysis of the works of foreign authors shows that energy-saving is a subject of scientific interest, but is considered in the context of the internal resources of the individual. Most of the works devoted to the study of issues related to the way in which to maintain or preserve their personal resources in modern conditions. So, C.N. Macrae, A.B. Milne, C.V. Bodenhausen experimentally confirmed that an important role for the energy saving of the person playing the so-called stereotypes existence [2]. The transition from the preservation of internal resources to realize the need to maintain the external (natural) resources, as well as to the formation of this skill is not a subject of intense scientific interest.

In Russian literature the concept of energy-saving competence gained some meaningful representation [3, 4]. As a rule, this competence structure is analyzed through the prism of the activity of specialists mainly technical profile. And viewed in the context of energy education.

In this study, under the energy-saving awareness of competence refers to a person with respect to energy-saving activities in which it implements competency integrated in the professional qualifications and experience.

A necessary condition for the formation of energy-saving competence is the development of personal qualities necessary for the implementation of various types of practices from the perspective of a reasonable power consumption. The composition of these properties reveals the following energy-saving components of competence:

- Value-motivational component is aimed at energy-saving, which in turn includes a plurality of motives and values hat define the social and personal awareness of the need for rational use of energy resources;

- Cognitive component involves knowledge of the theoretical foundations of energy and resources, knowledge in the field of innovations aimed at improving energy efficiency;

- The activity component is represented by a system of skills and abilities to apply energyecological knowledge in various activities;

- Reflective component is cross-cutting and is implemented in an adequate self-esteem of man's relationship to the actual environmental problems of our time, the assessment 
of cash knowledge and understanding of their own willingness to carry out professional activities in accordance with the principles of rational energy use.

Thus, the training of qualified personnel with "thinking energy-saver" and capable of timely, independent and creative adoption of energy-efficient solutions can not be based on the preferential development of theoretical knowledge. Formation of the corresponding competence requires a complex implementation of training and educational, classroom and extracurricular educational tools within the professional and educational space saving.

\section{The model of formation of energy-saving competence}

Structural-informative model of energy-efficient competence based on forecasting possible result and includes four interconnected blocks (Figure 1).

Task befor forecast unit determines the orientation of the development of follow-up and contains the requirements of employers to save energy; information on the receipt, transmission and use of sources of energy contained in the federal state educational standards and educational programs. The tasks are updated towards the goal. The components of energy-saving competencies characterize the logic of the educational process.

The implementation of the operational unit promotes activities to implement energysaving activities in all areas of human life through the integration of teaching, research and socio-cultural activities that determines the meaning of the formation of energy-saving expertise.

Reflective unit includes monitoring the formation of energy-saving competence by continuous or repetitive data gathering, representing a combination of certain key indicators of energy savings. The effectiveness of energy-saving characteristic of formation of competence is the educational and professional readiness of students to implement a methodology of energy-saving activities in all areas of modern life.

The proposed model became the basis for the determination of ongoing formation of energy-saving competence of students of secondary and vocational schools, the selection of interactive forms and methods of training, development of diagnostic tools for monitoring the process and the result of the formation of energy-ecological competence. 


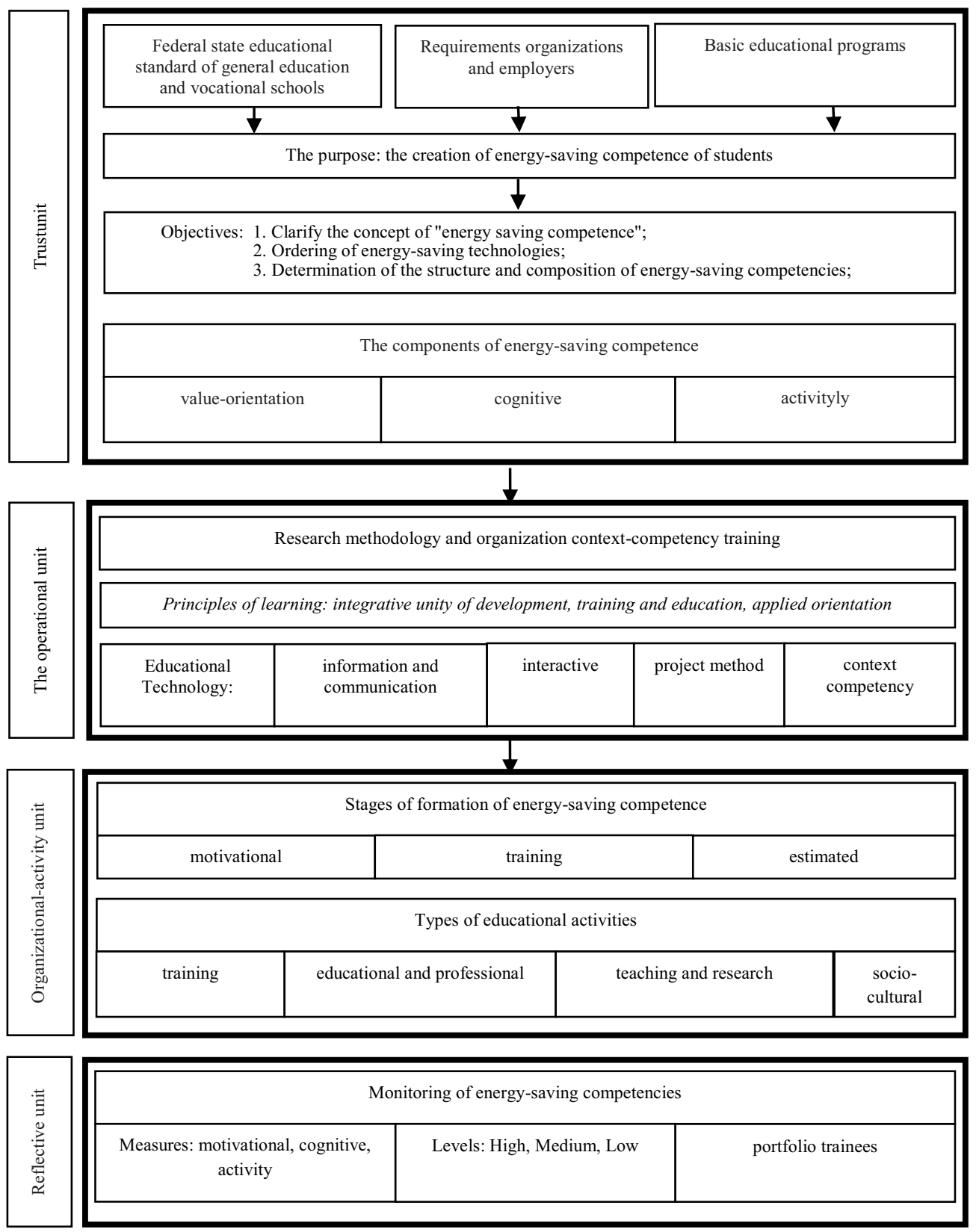

Fig. 1. Structural and informative model of energy saving competence of students in the (secondary), vocational school. 


\section{Educational technologies of formation of energy-saving competence}

In the process of putting into practice the formation of energy-saving model of competence must take into account the nature of the activities of the future expert, highlight the content of the planned subjects invariant and variable component reflecting the specifics of the area of expertise. The important place is occupied by the use of educational technologies. In our opinion, for the formation of energy-saving expertise in vocational education are the most effective personality-oriented technologies used within the context of learning.

Contextual learning is a successful attempt resolution of the basic contradiction of vocational education lies in the fact that mastery of professional activities should be provided as part of educational activity, qualitatively different in content, forms, methods, tools and processes [5]. As a means of implementing the theoretical approach in contextual training is offered in full use of active learning methods, namely:

- Discussion techniques that can be implemented in the form of a dialogue, participants or groups of participants, Socratic conversation, group discussion or "round table", "brainstorming", seminar-debate, case studies, etc.;

- Play methods and forms of training can significantly improve the interest of students, to strengthen their attention, deeply understand the essence of the phenomena being studied, and submit yourself as a corresponding future professional activity;

- Project method: depending on the content of disciplines, within which will be carried out the project activities, the theme of research may involve the use of non-traditional (alternative) sources of energy, the introduction of automation devices, controllers, ensuring the optimization of technological processes and lead to a decrease in energy consumption, carrying out energy audit, the creation of modern systems of accounting and control of energy consumption, the development and support of new technologies aimed at improving energy efficiency, etc.;

- Constructive methods of learning and teaching pilot situational basis. Analysis of specific situations (case study) allows us to apply theoretical knowledge to solve practical problems in conditions as close to reality;

- The use of interactive electronic content: the advantage of multimedia learning environments is the ability to simultaneously reproduce the text on the computer screen, video and audio in some collection-related and logically subordinate to a certain didactic concept.

It should also be noted that the formation of energy-saving competence of students requires energy culture among teachers of vocational training. It is essential that teachers have broad erudition, freely oriented in problematic issues of energy, environment, legal and regulatory framework of energy, energy conservation in the home, in the workplace, in public services. This problem can be solved by improving the system of retraining and advanced training.

\section{Conclusions and recommendations}

Formation of energy-saving competence requires compliance with the principle of ecological conformity educational environment, a key component of which, in our opinion, should be the energy management. 
Development of energy management, in addition to the optimization of the system (to achieve without major financial losses significant energy savings) associated with involvement in the energy management process of all participants in the educational process. The first step to understanding the objectives and principles of energy efficiency policy is transparency of energy consumption, open to students and teachers of educational institutions, the participation of students of technical training areas to monitor power consumption.

Organization of the system, a comprehensive work on the formation of energy-saving competence of the future teachers of vocational school promotes environmental awareness and implementation of state policy in the field of energy conservation and efficiency.

\section{References}

1. E.F.Zeer, E.E. Symanyuk, Competence approach as the factor of innovative education (2011)

2. C.N. Macrae, A.B. Milne, C.V. Bodenhausen, Stereotypes as energy-saving devices: A peek inside the cognitive toolbox (1994)

3. S.A. Rakutko, Energy education: competence approach (2010)

4. Y.I. Rakhimov, Pedagogical technology offormation of professional competence of students of technical colleges energy (2013)

5. A.A. Verbitsky, Contextual learning: the concept and content (2009) 